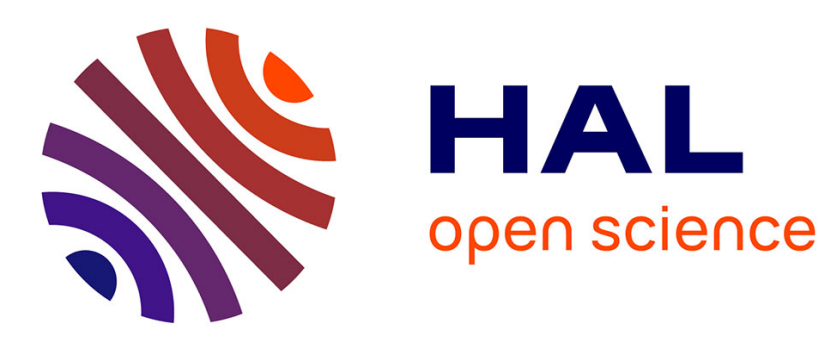

\title{
Phase matched doubly resonant third-harmonic generation in I 2-vapour
}

\author{
Tran Ba Chu, A. Bouvier, A.J. Bouvier, P. Crozet
}

\section{To cite this version:}

Tran Ba Chu, A. Bouvier, A.J. Bouvier, P. Crozet. Phase matched doubly resonant third-harmonic generation in I 2-vapour. Journal de Physique, 1989, 50 (2), pp.201-206. 10.1051/jphys:01989005002020100 . jpa-00210911

\section{HAL Id: jpa-00210911 https://hal.science/jpa-00210911}

Submitted on 1 Jan 1989

HAL is a multi-disciplinary open access archive for the deposit and dissemination of scientific research documents, whether they are published or not. The documents may come from teaching and research institutions in France or abroad, or from public or private research centers.
L'archive ouverte pluridisciplinaire HAL, est destinée au dépôt et à la diffusion de documents scientifiques de niveau recherche, publiés ou non, émanant des établissements d'enseignement et de recherche français ou étrangers, des laboratoires publics ou privés. 
Classification

Physics Abstracts

$42.65-42.65 \mathrm{C}$

\title{
Phase matched doubly resonant third-harmonic generation in $\mathbf{I}_{2}$-vapour
}

\author{
Tran Ba Chu (*), A. Bouvier, A. J. Bouvier and P. Crozet \\ Laboratoire de Spectrométrie Ionique et Moléculaire (associé au C.N.R.S. $\mathrm{n}^{\circ} 171$ ), Université \\ Lyon I, Bât. 205, 43 Bd du 11 Novembre 1918, 69622 Villeurbanne Cedex, France
}

(Reçu le 23 juin 1987, révisé le 4 mai 1988, accepté le 21 septembre 1988)

\begin{abstract}
Résumé. - A l'aide d'un laser pulsé utilisé en Rh6G pour produire la longueur d'onde fondamentale, nous avons enregistré le spectre d'excitation T.H.G. de la vapeur d'iode, en balayant la longueur d'onde du laser à colorant dans le domaine $5696<\lambda_{1}<5820 \AA \AA$. La variation de la puissance de sortie V.U.V. avec la température de la vapeur saturante d'iode a été étudiée à $\lambda_{\text {v.u.v. }}=1920,2 \AA \AA$. Nous avons déterminé la susceptibilité du troisième ordre $\chi^{(3)}$ pour cette longueur d'onde et la variation de la dispersion de la vapeur d'iode en fonction de la température.
\end{abstract}

\begin{abstract}
Using the pulsed output from a Rh6G dye laser for the fundamental wavelength, we have recorded the T.H.G. spectrum of $\mathrm{I}_{2}$-vapour, scanning the dye laser wavelengths between $5696<\lambda_{1}<5820 \AA$. The variation of the output V.U.V.-power with the saturation temperature of the iodine vapour has been studied at $\lambda_{\text {v.u.v. }}=1920.2 \AA$. The third-order susceptibility coefficient $\chi^{(3)}$ at this wavelength and the temperature dependence of the dispersion of the iodine vapour have been determined.
\end{abstract}

\section{Introduction.}

Frequency mixing and harmonic-generation have been carried out in the utraviolet region using non-linear crystals. In the vacuum ultraviolet (V.U.V.), however, these crystals generally become opaque and can no longer be used. The techniques of Sum-Frequency Mixing (S.F.M.) and Harmonic Generation (H.G.) in atomic and molecular vapours [1] have attracted a great deal of attention as a means of extending coherent radiation sources to the V.U.V.-region of the spectrum. Recently, Tai et al. [2, 3] have used the technique of thirdharmonic generation based on simultaneous resonances in one- and two-quantum transitions to find a level of symmetry ${ }^{1} \mathrm{O}_{\mathrm{g}}^{+}$of molecular iodine. They have shown that this technique is not as seriously limited by the photoionization process as the singly resonant method, and that it also has a high third-harmonic conversion efficiency. However, no details concerning the non-linear interaction process of the waves were given in their papers.

(*) Permanent address : Institute of Applied Physics Hanö-Vietnam. 
In the present experiment we have recorded the emission spectra of the T.H.G. in $\mathrm{I}_{2}$ vapour and we have studied the temperature dependence of the V.U.V.-power i.e. on the phase-matching condition, determined the third-order susceptibility of $\mathrm{I}_{2}$ in the region of $\lambda_{\text {V.U.V. }}=1920 \AA$ and its dispersion $\Delta n=n\left(\lambda_{\text {V.U.V. }}\right)-n\left(3 \lambda_{\text {V.U.V. }}\right)$. We have also observed the $X \leftarrow F$ doubly resonant three photon excitation spectrum of $I_{2}$ in the region 1899 $1940 \AA$.

\section{Experiment.}

A scheme of the experimental set-up is shown in figure 1. The light source is a Rh6G dye laser pumped by the S.H. of a pulsed YAG laser (Quantel). This Littman type dye laser constructed in our laboratory provided $10 \mathrm{~ns}$ long pulses with a bandwidth of $0.05 \AA$ at a repetition rate of $10 \mathrm{~Hz}$. The laser power was approximately $0.4 \mathrm{~mJ}$ per pulse at $5760 \AA$. The laser beam was focused with a $f=16 \mathrm{~cm}($ or $10 \mathrm{~cm})$ lens at the centre of a $10 \mathrm{~cm}$ long fused quartz cell containing $\mathrm{I}_{2}$-vapour. A Glan prism was put between the lens and the output mirror of the dye laser to ensure that the light was almost $100 \%$ linearly polarized. Thirdharmonic generation in the cell was separated from the laser beam by means of a V.U.V.monochromator (Mc Pherson) and was detected by a solar blind photomultiplier (Model EMI G26 H315) which had a quantum efficiency of $13 \%$ at $1950 \AA$. The output signal of the photomultiplier was integrated by a boxcar integrator (Model PAR 162/164) and recorded on a chart recorder. The gate width of the boxcar was $250 \mathrm{~ns}$ and the integration time constant $10 \mu \mathrm{s}$. The dye laser wavelength was measured with an accuracy of $0.02 \AA$ using a Fizeau wave-meter (Laser Technics model 100) and an IBM micro-computer. A $100 \mathrm{MHz}$ oscilloscope was used to control the time positions of the gate and the signal.

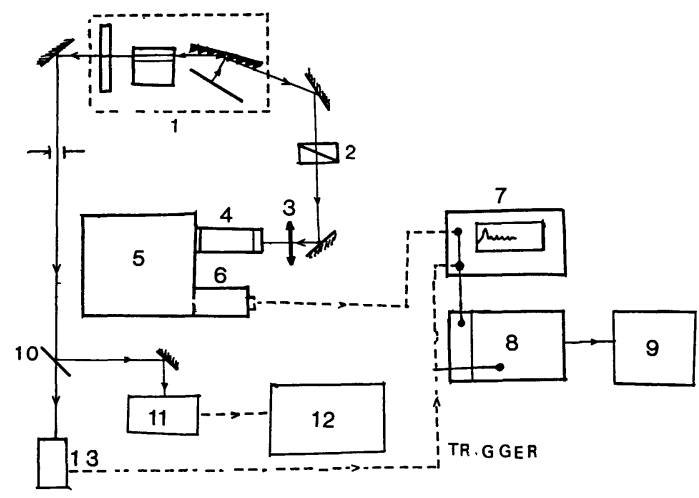

Fig. 1. - Schematic diagram of the apparatus, $1:$ Rh6G dye laser. 2. Glan prism. $3:$ Focusing lens. 4 : $\mathrm{I}_{2}$-cell. 5 : V.U.V.-monochromator. 6 : Solar Blind EMI-PM tube. 7 : Oscilloscope. 8 : Boxcar PAR 162/164. 9 : Recorder. 10 : Semi-reflecting mirror. 11 : Wave-meter. 12 : Computer. 13 : Photodiode.

In the first experiment the T.H. signal was recorded by scanning the dye laser wavelength in the region 5 696-5 $820 \AA$. Figure 2 shows a part of this spectrum. To ensure that the generated signals were indeed due to T.H.G., either the $\mathrm{I}_{2}$-cell was cooled by liquid nitrogen or the fundamental beam was circularly polarized. In both cases no signal was detected.

The above-mentioned T.H.G. spectrum is due to simultaneous resonances in one- and twoquantum transitions [2]. Our spectrum is not part of the Cordes band system [5], or of the fluorescence spectrum reported by Kalatani et al. [6]. At room temperature $\left(20.5^{\circ} \mathrm{C}\right)$, using focusing lens of $16 \mathrm{~cm}$ focal length at laser wavelength $5760.5 \AA$, one had a power of T.H.G. 


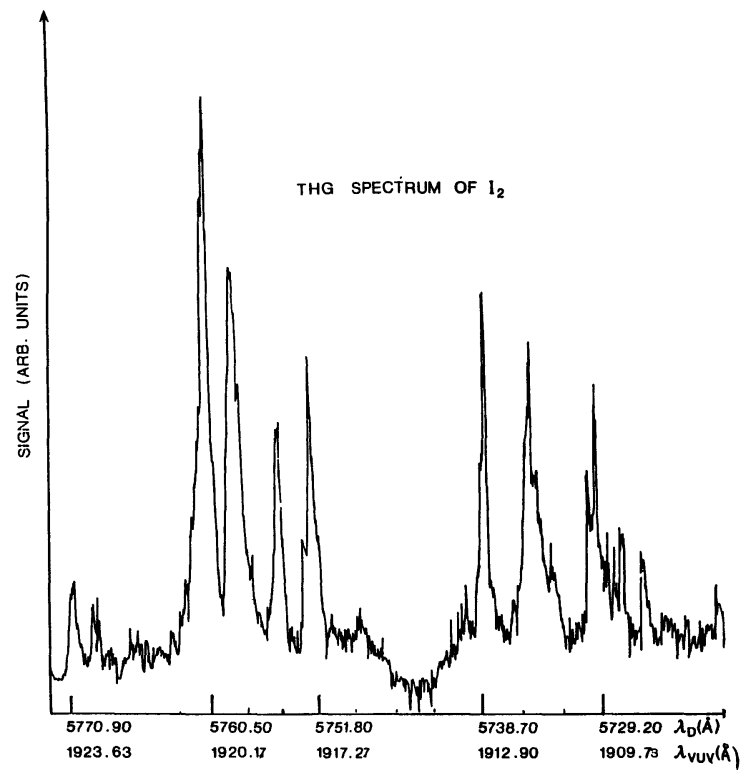

Fig. 2. - Wavelength dependence of the generated T.H. power.

corresponding to $4.2 \times 10^{5}$ V.U.V.-photons generated per pulse, an energy conversion ratio of $1.0 \times 10^{-9}$.

The temperature dependence of T.H.G. power at the wavelength $\left(\lambda_{\text {V.U.V. }}=1920.2 \AA\right.$ ) was investigated using two lenses of different focal lengths $\left(f_{1}=16 \mathrm{~cm}\right.$ or $\left.f_{2}=10 \mathrm{~cm}\right)$. In the experiments the temperature of the $\mathrm{I}_{2}$-cell was varied continuously from $0{ }^{\circ} \mathrm{C}$ to $20.5{ }^{\circ} \mathrm{C}$.

Figure 3 shows the variation of the T.H. power with temperature, i.e. with the number of iodine molecules per $\mathrm{cm}^{3}$ [7]. From figure 3 , it is obvious that the optimum T.H.G. power

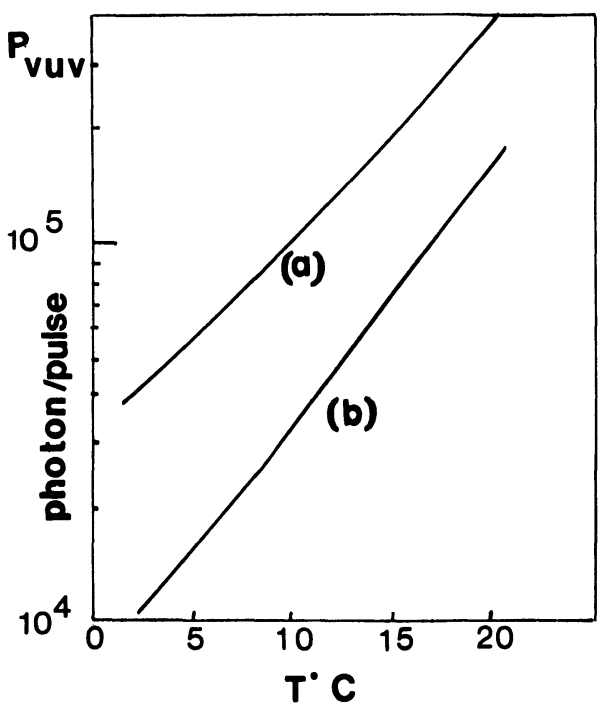

Fig. 3. - Dependence of the generated V.U.V. power at $\lambda_{\text {v.u.v. }}=1920.2 \AA$ versus the temperature. (a) $f=16 \mathrm{~cm}$. (b) $f=10 \mathrm{~cm}$. 
output will be reached above room temperature. Unfortunately, and investigation at temperatures higher than $21 .{ }^{\circ} \mathrm{C}$ was not possible in this experimental set-up.

\section{Third-order susceptibility $\chi^{(3)}$ at the wavelength $\lambda_{\text {v.u.v. }}=1920.2 \AA$ and dispersion $\Delta n$ of the $I_{2}$-vapour.}

Theoretically, the magnitude of the third-order susceptibility $\chi^{(3)}$ of atomic gases can be determined by the perturbation theory. In the case of iodine vapour, results of ab-initio $\chi^{(3)}$ calculations are not yet available, and so we have used here the experimental value of $\chi^{(3)}$

In the case of tight focusing of the fundamental wave, from [8] we have the formula

$$
P_{\text {V.U.V. }}^{(3)}=\frac{12(2 \pi)^{8}\left|\chi^{(3)}\right|^{2} P_{01}^{3} \sigma_{3}^{2} \exp \left(-2 \sigma_{3}\right) N^{2}}{c^{2} \lambda_{1}^{4} n_{\text {V.U.V. }} n_{1}^{3}}
$$

where $P_{\text {V.U.v. }}^{(3)} P_{01}$ are the powers of generated- and fundamental-waves respectively,

$$
\sigma_{3}=-\frac{b \Delta k}{2}
$$

is the phase-matching parameter with

$$
\Delta k=k_{\mathrm{V} . \mathrm{U} . \mathrm{V} .}-3 k_{1}=\left(6 \pi / \lambda_{1}\right)\left(n_{\mathrm{V} . \mathrm{U} . \mathrm{V} .}-n_{1}\right) ;
$$

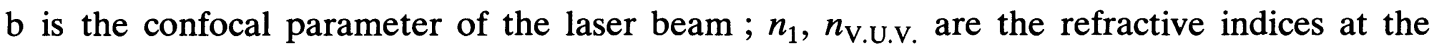
wavelengths $\lambda_{1}$ and $\lambda_{\text {V.U.V. }}=\lambda_{1} / 3$ respectively; $N$ is the number of molecules per $\mathrm{cm}^{3} ; c$ is the velocity of light in vacuo.

The confocal parameter is determined by an expression given by Kleinman [9]

$$
b=8 \lambda_{1} n_{1}^{2}\left(\frac{f}{a}\right)^{2}
$$

where $a$ is the diameter of the laser beam at entrance face of the focusing lens.

For constant values of temperature and wavelength, the ratio of the generated V.U.V. power using lenses of focal length $f_{1}$ and $f_{2}$ can be found from expressions (1) and (3), taking $n_{1} \simeq 1$. This ratio is given by

$$
\frac{V_{f_{1}}}{V_{f_{2}}}=\left(\frac{f_{1}}{f_{2}}\right)^{4} \exp \left(\frac{48 \pi\left(f_{1}^{2}-f_{2}^{2}\right)}{a^{2}} \Delta n\right)
$$

where $V_{f_{1}}$ and $V_{f_{2}}$ are the magnitudes of the corresponding averaged output voltage at the boxcar integrator. From equations (2), (3), (4) we have

$$
\sigma_{3\left(f_{1}\right)}=-\frac{f_{1}^{2}}{2\left(f_{1}^{2}-f_{2}^{2}\right)}\left(\operatorname{Ln} \frac{V_{f_{1}}}{V_{f_{2}}}+4 \operatorname{Ln} \frac{f_{2}}{f_{1}}\right) .
$$

From (5), it is obvious that $a$ and $b$ are absent in the determination of the values of $\sigma_{3}$.

At room temperature and at $\lambda_{\text {V.U.V. }}=1920.2 \AA$, we measured

$$
V_{\left(f_{1}=16 \mathrm{~cm}\right)}=7.8 \mathrm{~V}, \quad V_{\left(f_{2}=10 \mathrm{~cm}\right)}=2.7 \mathrm{~V} .
$$


From equation (5) we obtained $\sigma_{3\left(f_{1}\right)}=0.67$. Given that the peak power of our dye laser $P_{01}=40 \mathrm{~kW}$ produced a V.U.V.-peak power of $P_{\mathrm{V} . U . \mathrm{V}}=4.5 \times 10^{-5} \mathrm{~W}\left(4.2 \times 10^{5} \mathrm{~V} . \mathrm{U} . \mathrm{V}\right.$. photons/pulse) at room temperature $\left(N=6 \times 10^{15}\right.$ molecules $\left./ \mathrm{cm}^{3}\right)$, we obtained from (1)

$$
\chi^{(3)}=7.4 \times 10^{-34} \text { e.s.u. }
$$

This result shows that $I_{2}$-vapour is a suitable non-linear medium for third-order sumfrequency mixing, like a metal vapour.

Using $a=0.6 \mathrm{~cm}$, the curves $(a),(b)$ in figure 3 and the expression (4) yield the value of the dispersion $\Delta n$. Figure 4 shows the dependence of $|\Delta n|$ on the temperature of $I_{2}$-vapour. At room temperature, using $n=1.001920$ [10], from the above results we obtained the refractive index of $\mathrm{I}_{2}$-vapour at wavelength $\lambda_{\text {v.U.v. }}=1920.2 \AA$ and room temperature

$$
n(1920.2 \AA)=1.00192 \pm 1 \times 10^{-5} \text {. }
$$

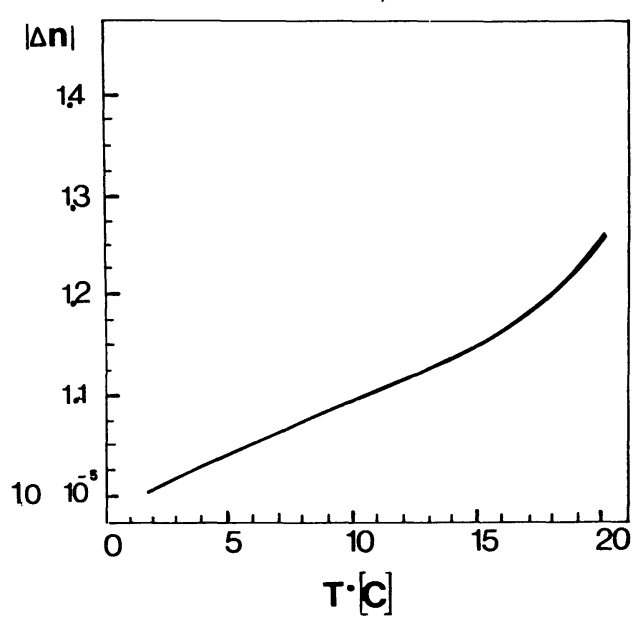

Fig. 4. - Dependence of the dispersion $|\Delta n|$ of the $I_{2}$-vapour on the temperature (at wavelengths $\lambda_{\text {V.U.v. }}=1920.2 \AA$ and $\lambda_{1}=5760.9 \AA$ ).

\section{Conclusion.}

Upconversion of visible dye laser radiation by third-harmonic technique in iodine molecular vapour was investigated. We have determined the value of the third-order susceptibility $\chi^{(3)}$ of $\mathrm{I}_{2}$-vapour in the case of simultaneous resonance in one- and two-quantum transitions. We conclude that $I_{2}$-vapour is capable of acting as a non-linear medium for third-order sumfrequency mixing.

\section{References}

[1] ReIntJes, J. F., Non-linear optical parametric processes in liquids and gases (Academic Press, Inc.) 1984.

[2] Tai, C., Dably, F. W. and Giles, G. L., Phys. Rev. 20 (1979) 233. 
[3] TAI, C., Phys. Rev. 23 (1981) 2462 ;

TAI, C. and TARn, A., Phys. Rev. 27 (1982) 3078 ;

TAI, C., Phys. Rev. 30 (1984) 1812.

[4] Kramer, S. D., Chen, Ch. H. and Payne, M. G., Opt. Lett. 9 (1984) 347.

[5] Cordes, V. H., Z. Phys. 97 (1935) 603.

[6] Kasatani, K., Tanaka, Y., Shibuya, K., Kawasaki, M., Obi, K., Sato, H. and Tanaka, I., J. Chem. Phys. 74 (1981) 895.

[7] Baxtu, S. and Grese, I., J. Am. Chem. Soc. 37 (1915) 1061.

[8] Fischer, R., and Wieczorek, L. W., Ann. Phys. 35 (1978) 389.

[9] Kleinman, D. A., Phys. Rev. 128 (1962) 1761.

[10] Handbook of Chemistry and Physics, 60th Ed. (C.R.C.). 